\title{
Effect of Sex-Sorted Sperm Dosage on Conception Rates in Holstein Heifers and Lactating Cows
}

\author{
J. M. DeJarnette, ${ }^{\star 1}$ R. L. Nebel, ${ }^{\star}$ C. E. Marshall, ${ }^{\star}$ J. F. Moreno, $†$ C. R. McCleary, $†$ and R. W. Lenz† \\ *Select Sires Inc., Plain City, OH 43064 \\ †Sexing Technologies Inc., Navasota, TX 77868
}

\begin{abstract}
Ejaculates were collected by artificial vagina from 3 Holstein sires and sorted to $90 \%$ purity for X-chromosome-bearing spermatozoa (range 88 to $93 \%$ ) using flow cytometry. Sorted sperm were diluted to $2.1,3.5$, or 5.0 $\times 10^{6}$ sperm per dose in an egg yolk (20\%), Tris, glycerol $(7 \%)$ extender. Collections were repeated until $>600$ straws per sperm dose per sire were obtained. Each sperm dose was loaded into color-coded 0.25-mL French straws, with alternate colors used to define treatments across sires. Within sires, straws were packaged at 9 per cane (3 of each color) and strategically allocated to 75 Holstein herds with targets for $50 \%$ use in heifers and $50 \%$ in lactating cows. Straw color was recorded in the on-farm record-keeping system at the time of insemination. Data were analyzed separately for cows and heifers. Among heifers, a total of 2,125 usable records were retrieved from 51 herds ( $238 \pm 5.5$ services/ sperm dose per sire, range: 218 to 263 ). Conception rates in heifers were influenced by the sire $\times$ sperm dosage interaction. Within sire $\mathrm{A}$, conception rates of heifers were greater for the $5 \times 10^{6}(59.5 \%)$ than for the $2.1 \times 10^{6}(46.4 \%)$ sperm dose and intermediate for the $3.5 \times 10^{6}$ sperm dose (52.2\%). However, across sires, sperm dosage had no effect on heifer conception rates $\left(46.7,51.2\right.$, and $52.5 \%$ for the $2.1,3.5$, and $5.0 \times 10^{6}$ sperm dosages, respectively). Among cows, a total of 2,369 services were retrieved from 56 herds ( $263 \pm 8.8$ services/sperm dose per sire, range: 233 to 303 ). Conception rates of cows $(29.4 \%)$ were not affected by sire or sperm dosage $(27.0,29.1$, and $30.3 \%$ for the $2.1,3.5$, and $5.0 \times 10^{6}$ sperm dosages, respectively). In conclusion, these data indicate that an increased sperm dosage may enhance virgin heifer conception rates for some (but not all) sires, whereas neither sire nor sexed-sperm dosage affected conception rates of lactating cows. Additional studies of sexed-sperm dosage across a larger
\end{abstract}

Received December 19, 2007.

Accepted January 22, 2008.

${ }^{1}$ Corresponding author: jmdejarnette@selectsires.com sampling of bulls are warranted to determine whether and how such a practice can be implemented cost effectively for the benefit of the dairy industry.

Key words: sexed semen, sperm dosage, flow cytometry, conception rate

\section{INTRODUCTION}

Gender preselection has been one of the most soughtafter reproductive biotechnologies of all time. Although numerous theoretical methods for sex-sorting spermatozoa have been studied, only the flow cytometric procedure reported by Garner et al. (1983) has proven to be a reliable and repeatable method of distinguishing Xand Y-chromosome-bearing sperm populations. Johnson et al. (1989) were the first to validate this technology with the birth of live offspring of the predicted sex. Numerous studies conducted in the 1990s focused on refinement of this technology for adaptation to commercial application in the bovine (Schenk et al., 1999; Seidel et al., 1999) and, in the process, researchers documented that this sorting procedure can consistently produce $\sim 90 \%$ gender bias among resulting offspring. However, these and other studies (Seidel and Garner, 2002; Seidel, 2007) have also revealed the highly invasive nature of the procedure, which appears to have detrimental effects on sperm viability and quality. Furthermore, the equipment expense, speed, and sorting efficiency economically dictate that commercial application is presently possible only with extremely low $(\sim 2$ million) sperm numbers per insemination dose (Amann, 1999). For these reasons, commercial application and most research conducted to date have focused on the use of sex-sorted semen in virgin heifers to capitalize on the greater opportunity for conception (compared with lactating cows), and thereby the greater opportunity for return on investment for the producer adopting this novel and expensive technology.

Recent reports have indicated that commercial application in the United States is largely considered successful although, as expected, conception rates in virgin heifers are approximately 70 to $80 \%$ of those obtained by using conventional semen (DeJarnette et al., 2007). 
What is not clear from the limited studies available to date is what portion of this compromised conception potential with sex-sorted semen is due to the sexing process per se vs. simply an effect of subthreshold sperm numbers per dose (Salisbury and Van Demark, 1961; den Daas et al., 1998; Seidel and Schenk, 2007). Furthermore, although it has been generally accepted that use of sexed semen in lactating dairy cows would not be economically advisable because of the inherently lower conception potential, trials documenting the actual conception rates achieved are limited (Schenk and Everett, 2007). Considering the prospects for development of more efficient sperm-sorting procedures (Seidel, 2007), the objective of this study was to determine the effect of sperm dosage on conception rate of Holstein virgin heifers and lactating cows inseminated with sexsorted semen.

\section{MATERIALS AND METHODS}

Three Holstein sires with August 2006 USDA genetic evaluations were selected for this study. To be eligible for the study, each sire was required to 1) have PTA for calving ease that were below breed average, 2) have a history of producing semen with $>80 \%$ normal sperm morphology, and 3) have a documented fertility potential of breed average or better as assessed by both inhouse and industry evaluation systems (estimated relative conception rate, Dairy Records Management Services, Raleigh, NC). Ejaculates were collected via artificial vagina and screened for normal sperm morphology at $600 \times$ magnification by using differential interference contrast optics after fixing a $10-\mu \mathrm{L}$ sample of neat semen in $0.5 \mathrm{~mL}$ of Tyrode's albumin lactate pyruvate buffer containing $0.2 \%$ formalin. Abnormalities related to sperm head defects were classified as primary defects, and defects involving the sperm tail were classified as secondary abnormalities (Barth and Oko, 1989). Samples with $<80 \%$ normal sperm morphology were rejected. Samples with $\geq 80 \%$ normal sperm morphology were sex-sorted for X-chromosome-bearing sperm according to procedures described previously (Garner and Seidel, 2002; Seidel, 2007). A split ejaculate technique was not practical for this study because of the inefficient nature of the sorting process, which would have yielded too few doses per treatment within ejaculate $(\sim 25)$ to provide meaningful statistical power. Individual ejaculates were extended to $8.4,14.0$, or $20 \times 10^{6} \mathrm{sperm} / \mathrm{mL}$ in a Tris, egg yolk, $7 \%$ glycerol extender and packaged in 0.25-mL French straws to provide AI dosages of 2.1, 3.5 , or $5.0 \times 10^{6}$ sperm, respectively. Within sire, dosages were identified by color-coded straws; however, color codes were alternated across sires to avoid the potential for perception bias during field use. A total of
$>600$ straws/dosage per sire were processed for field use. Straws were frozen in liquid nitrogen vapor at rates within documented tolerance limits (Robbins et al., 1976) before plunging them in liquid nitrogen. Sample straws were thawed in $37^{\circ} \mathrm{C}$ water for 1 min before evaluation for progressive sperm motility. Sperm motility and acrosome integrity were also evaluated in sample straws after $3 \mathrm{~h}$ of incubation at $37^{\circ} \mathrm{C}$. Motility evaluations were subjective visual estimates of 5 or more random fields of view (avoiding slide perimeter) at $200 \times$ magnification by using phase-contrast optics and were rounded to the nearest $5 \%$. Acrosomal integrity evaluations were conducted at $400 \times$ magnification by using differential interference contrast optics (Saacke and Marshall, 1968). The results of postthaw semen quality evaluations by treatment within bull are presented in Table 1 . The postsort purity of X-chromosome-bearing spermatozoa (Welch and Johnson, 1999) averaged $91 \pm 0.15 \%$ (range: 88 to $93 \%$ ).

Straws were packaged 9 per cane (3 straws of each color/treatment) to facilitate balanced and random field use. Within sire, half the semen (300 straws/sperm dosage per sire) was designated for use in virgin heifers and the other half for use in lactating cows. Research herds were selected based on evidence from on-farm records that the herd had the potential to achieve conception rates $\geq 60 \%$ in virgin heifers, $\geq 30 \%$ in lactating cows, or both. Each herd used a minimum of 27 total doses (9/treatment of any combination of sires) for each parity group selected. Fifty-one herds used sexed semen in heifers, and 56 herds used sexed semen in lactating cows. Herds were required to use semen in a random fashion within 2 mo of delivery. At the time of AI, straw color was recorded in the on-farm computer records as an attachment to the sire identification. Pregnancy was diagnosed at 30 to $50 \mathrm{~d}$ after AI according to each farm's standard operating procedures (rectal palpation, ultrasound, or both). On completion of the study, an electronic backup of on-farm records was used to retrieve insemination information for both the experimental sexed semen and for any conventional semen that was used concurrently.

Recommendations for semen use were as follows: synchronization of estrus was acceptable, but semen should be used only in females displaying standing estrus. The use of experimental semen at fixed-time $\mathrm{AI}$ or in the absence of observed standing estrus was discouraged. Inseminations should occur 8 to $12 \mathrm{~h}$ after initial detection of estrus. Cows should be 60 and $150 \mathrm{~d}$ postcalving at the time of AI, with no evidence of calving problems, metritis, or early postpartum metabolic disorders.

Heifer and lactating-cow data were analyzed separately by least squares means ANOVA and $\chi^{2}$ statistics. All models included the effects of sperm dosage, herd, 
Table 1. Descriptive statistics of semen production and quality characteristics ${ }^{1}$ of sex-sorted semen of 3 Holstein sires used in this study

\begin{tabular}{cccccccc}
\hline & & & & & & \multicolumn{2}{c}{ Abnormalities } \\
\cline { 7 - 9 } Sire & $\begin{array}{c}\text { Sperm dose, } \\
\times 10^{6}\end{array}$ & $\begin{array}{c}\text { Ejaculates, } \\
\mathrm{n}\end{array}$ & $\begin{array}{c}\text { Motility, } \\
0 \mathrm{~h}\end{array}$ & $\begin{array}{c}\text { Motility, } \\
3 \mathrm{~h}\end{array}$ & $\begin{array}{c}\text { Acrosome } \\
\text { integrity } 3 \mathrm{~h}\end{array}$ & Primary & Secondary \\
\hline $\mathrm{A}$ & 2.1 & 3 & $60 \pm 1.4$ & $51 \pm 1.9$ & $73 \pm 0.7$ & $3.3 \pm 1.2$ & $6.3 \pm 0.9$ \\
& 3.5 & 4 & $62 \pm 4.9$ & $57 \pm 5.7$ & $75 \pm 2.8$ & $3.8 \pm 1.1$ & $4.8 \pm 1.1$ \\
& 5.0 & 7 & $63 \pm 1.8$ & $57 \pm 0.8$ & $79 \pm 1.1$ & $3.7 \pm 1.3$ & $7.1 \pm 1.2$ \\
$\mathrm{~B}$ & 2.1 & 3 & $53 \pm 5.2$ & $47 \pm 6.6$ & $72 \pm 3.9$ & $6.0 \pm 1.7$ & $7.7 \pm 2.9$ \\
& 3.5 & 5 & $50 \pm 2.4$ & $40 \pm 2.8$ & $66 \pm 2.8$ & $6.2 \pm 1.8$ & $6.6 \pm 1.0$ \\
& 5.0 & 8 & $52 \pm 1.2$ & $48 \pm 1.6$ & $71 \pm 1.7$ & $7.1 \pm 1.1$ & $8.0 \pm 1.0$ \\
$\mathrm{C}$ & 2.1 & 3 & $60 \pm 0.0$ & $51 \pm 1.4$ & $73 \pm 1.9$ & $4.7 \pm 0.9$ & $4.3 \pm 0.3$ \\
& 3.5 & 5 & $67 \pm 1.2$ & $64 \pm 2.3$ & $79 \pm 3.0$ & $3.0 \pm 0.7$ & $4.0 \pm 1.0$ \\
& 5.0 & 6 & $64 \pm 1.7$ & $57 \pm 2.6$ & $80 \pm 1.4$ & $4.8 \pm 0.7$ & $4.7 \pm 1.3$ \\
\hline
\end{tabular}

\begin{abstract}
${ }^{1}$ Sperm motility evaluations were performed at $200 \times$ magnification using phase contrast optics after thawing in a $37^{\circ} \mathrm{C}$ water bath and incubating for 0 or $3 \mathrm{~h}$. Acrosome integrity evaluations were performed at $400 \times$ magnification by using differential interference contrast optics after thawing and incubating sample straws in a $37^{\circ} \mathrm{C}$ water bath for $3 \mathrm{~h}$. Sperm morphology of each ejaculate was screened before sorting and was performed at $600 \times$ magnification by using differential interference contrast optics after fixing in a Tyrode's albumin lactate pyruvate buffer containing $0.2 \%$ formalin. Abnormalities of the sperm head were classified as primary abnormalities and defects of the sperm tail were classified as secondary. Ejaculates with $>20 \%$ total sperm abnormalities were discarded before sorting.
\end{abstract}

sire, and all 2-way interactions of these main effects. Models used for analysis of lactating cow data also included the effects of parity $(1,2$, or $\geq 3)$ and DIM at AI. Any comparison of conventional and sexed semen conception rates were performed as discussion points only and were not statistically analyzed because of the inconsistencies in use and application of these products. The mean and range in conception rates achieved with both sexed-sorted semen and conventional semen were estimated in subsets of data containing only those herds that used $\geq 50$ doses of either respective semen source (sex or conventional) in heifers or cows, respectively. The 50-service minimum was established for these comparisons to partly diminish the impact of binomial variation on estimates of herd conception potential. All analyses were performed by using SAS JMP Statistical Discovery Software (version 6.0.3; SAS Institute, Cary, NC).

\section{RESULTS}

\section{Virgin Heifers}

A total of 2,125 services were recovered from use in virgin heifers, which provided a mean of $238 \pm 5.5$ services per sperm dosage within sire (range: 218 to 263 ) and approximately 708 services for each respective sire or sperm dosage. The average age at AI for heifers bred to sexed semen $(432 \pm 1.11$ d for 1,239 heifers with available birth dates) was not different $(P>0.10)$ within and across sires and sperm dosages. Conception rates in virgin heifers were influenced $(P<0.001)$ by herd and tended $(P=0.11)$ to be influenced by the sire $\times$ sperm dosage interaction $(P=0.11$; Table 2 and Figure 1). A significant $(P<0.05)$ response in conception rate to increasing sperm dosages was observed within sire A. Conception rates within sire B were numerically greater $(P=0.06)$ for the 3.5 and $5.0 \times 10^{6}$ sperm dosages than for the $2.1 \times 10^{6}$ sperm dosage, whereas sperm dosage had no effect on conception rates within sire C. Across sires, the main effect of sperm dosage was not significant $(P>0.05 ; 46.7,51.2$, and $52.5 \%$ for the 2.1 , 3.5 , and $5.0 \times 10^{6}$ sperm dosages, respectively). Across sperm dosages, the main effect of sire was significant $(P<0.05)$, with sire $\mathrm{C}$ achieving greater conception rates $(53 \%)$ than sire $\mathrm{B}(41 \%)$ and with sire A being intermediate $(46 \%)$. Among herds $(\mathrm{n}=14)$ that used $\geq 50$ doses of sexed semen, conception rates averaged $47 \pm 3.2 \%$ (range: 33 to $68 \%, \mathrm{n} /$ herd $=75 \pm 4.7$ ). Among herds $(\mathrm{n}=10)$ that reported use of $\geq 50$ doses of conventional semen during the course of the study, conception rates averaged $43 \pm 3.6 \%$ (range: 29 to $61 \%$, n/herd $=$ $236 \pm 43$ ). The average age at AI for heifers bred to conventional semen $(\mathrm{n}=2,241$ with available birth dates) was $473 \pm 1.17 \mathrm{~d}$.

Table 2. Analysis of variance table of model effects included in analysis of heifer data

\begin{tabular}{lrrcc}
\hline Source & df & $\begin{array}{c}\text { Sum of } \\
\text { squares }\end{array}$ & F-ratio & Probability \\
\hline Herd & 50 & 21.15 & 1.79 & $<0.001$ \\
Dose & 2 & 0.91 & 1.93 & 0.15 \\
Sire ID & 2 & 1.51 & 3.20 & 0.04 \\
Herd $\times$ dose & 100 & 22.12 & 0.94 & 0.66 \\
Dose $\times$ sire ID & 4 & 1.79 & 1.89 & 0.11 \\
\hline
\end{tabular}




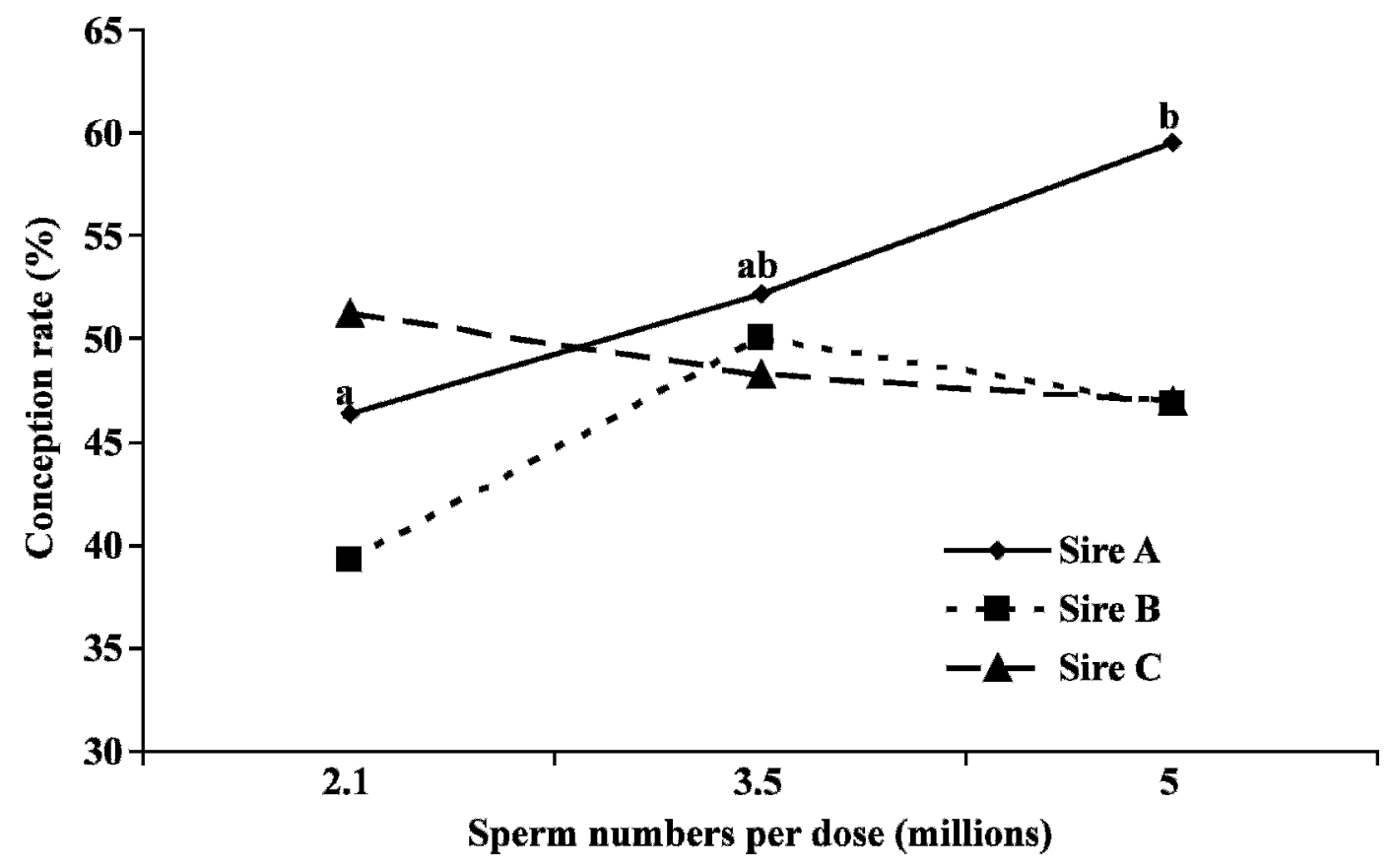

Figure 1. Effects of sire and sexed-sperm dosage on conception rates in virgin Holstein heifers. ${ }^{a, b}$ Values within sire lacking common letters differ, $P<0.05$. Sire effect, $P<0.05$. Sperm dosage effect, $P=0.15$. Sire $\times$ sperm dosage interaction, $P=0.11$.

\section{Lactating Cows}

A total of 2,369 services were recovered from the use of experimental semen in lactating cows, which provided a mean of $263 \pm 8.8$ services per sperm dosage within sire (range: 233 to 303 ) and approximately 790 services for each respective sire or sperm dosage. The random assignment of straws to cows of various parities $(1.9 \pm 1.2)$ and days postpartum $(86 \pm 0.90 \mathrm{~d})$ was not different $(P>0.10)$ within and across sires and sperm dosages. Conception rates tended $(P=0.12)$ to be influenced by parity but were not affected by any other main effect or interaction (Table 3). First- and second-parity cows achieved numerically greater conception rates (30.4, 368/1,212 and 31.1, 185/595, respectively) than did cows of third or greater parity $(25.6,144 / 562)$. These data provided little evidence that conception rates of

Table 3. Analysis of variance table of model effects included in analysis of lactating cow data

\begin{tabular}{lrccc}
\hline Source & df & $\begin{array}{c}\text { Sum of } \\
\text { squares }\end{array}$ & F-ratio & Probability \\
\hline Herd & 55 & 12.4 & 1.11 & 0.28 \\
Sperm dose & 2 & 0.29 & 0.71 & 0.49 \\
Sire ID & 2 & 0.31 & 0.75 & 0.47 \\
Herd $\times$ dose & 110 & 21.06 & 0.94 & 0.66 \\
Dose $\times$ sire ID & 4 & 1.15 & 1.42 & 0.23 \\
Parity & 2 & 0.87 & 2.15 & 0.12 \\
Days postpartum & 7 & 0.53 & 0.37 & 0.92 \\
\hline
\end{tabular}

lactating Holstein cows were influenced by sex-sperm dosage either within (Figure 2$)$ or across sires $(P>0.05$; $27.0,29.1$, and $30.3 \%$ for the $2.1,3.5$, and $5.0 \times 10^{6}$ sperm dosages, respectively). Across sperm dosages, the main effect of sire was not significant $(P>0.05 ; 25.7$, 25.4 , and $30.1 \%$ for sires $\mathrm{A}, \mathrm{B}$, and $\mathrm{C}$, respectively). Because of recommendations for selective use of this experimental semen in the early postpartum period, there was little variation in DIM at AI $(80 \pm 1.6 \mathrm{~d})$ and thereby, not surprisingly, no effect $(P=0.92)$ on conception rates. Although herd had no effect on conception in the full model (Table 3), the herd became significant $(P<0.01)$ after removing other nonsignificant main effects and interactions. Among herds $(n=13)$ that used $\geq 50$ doses of sexed semen, conception rates averaged $30 \pm 2.4 \%$ (range: 15 to $41 \%, \mathrm{n} / \mathrm{herd}=89 \pm 7.1$ ). Among herds ( $n=26$ ) that reported use of $\geq 50$ doses of conventional semen during the course of the study, conception rates averaged $30 \pm 1.0 \%$ (range: 21 to $39 \%$, n/herd = $642 \pm 103)$.

\section{DISCUSSION}

Appropriate interpretation of the present data necessitates a thorough understanding of the principles for semen dilution, as first proposed by Salisbury and Van Demark (1961). These principles predict that bulls will respond to increasing sperm dosages in an asymptotic fashion but that both the rate and the asymptote will 


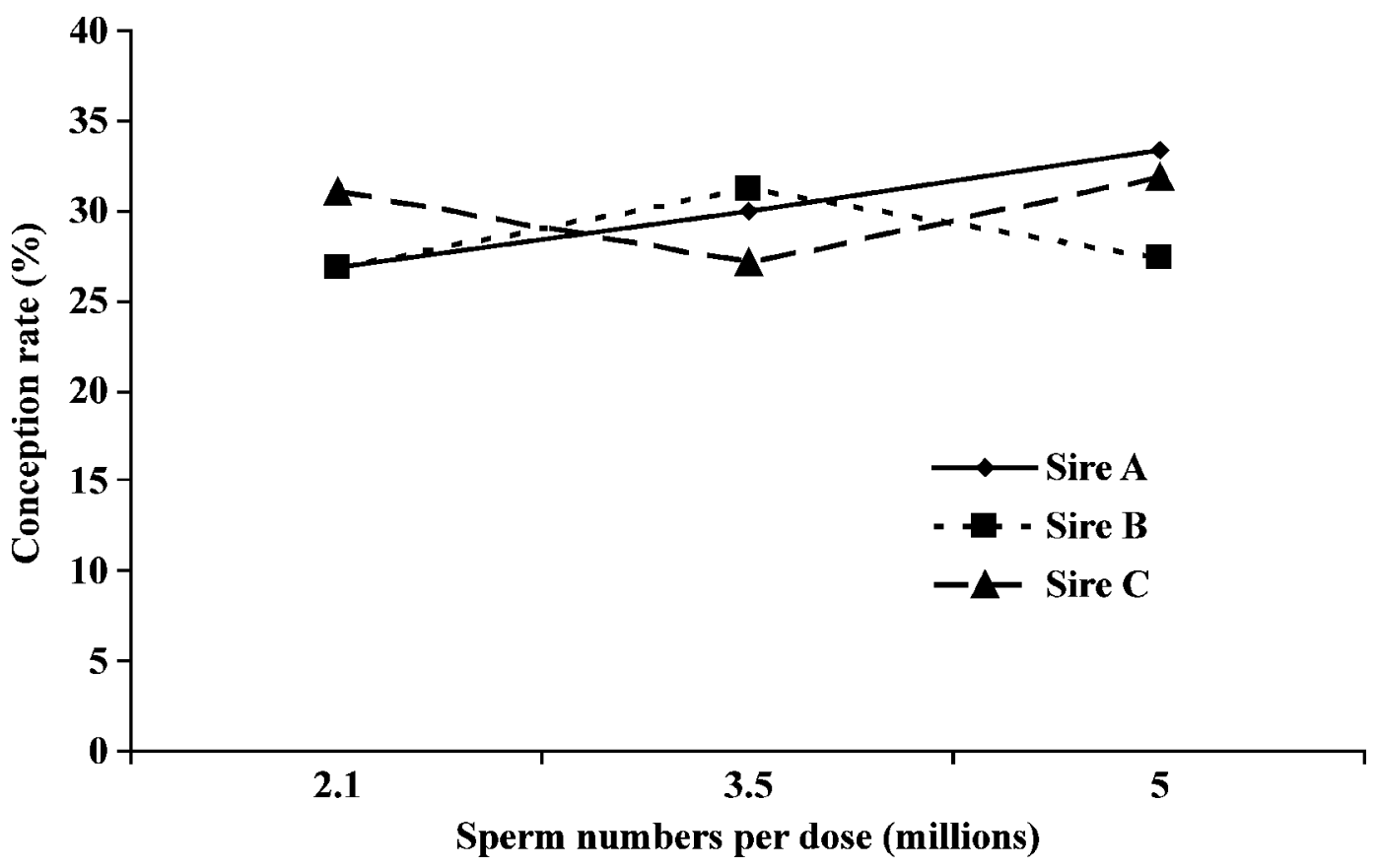

Figure 2. Effects of sire and sexed-sperm dosage on conception rates in lactating Holstein cows. Sire effect, $P=0.47$. Sperm dosage effect, $P=0.49$. Sire $\times$ sperm dosage interaction, $P=0.23$.

vary greatly among bulls because of intrinsic semen quality factors inherent to each sire (ejaculate). The rate at which bulls respond to increased sperm dosage is a function of the level of compensable sperm defects in the sample, which are largely believed to be related to measures of sperm viability (Saacke, 1998). Thereby, if a sample contains a poor percentage of viable sperm, this can often be compensated for by simply adding more sperm to each dose. In contrast, the maximum fertility potential that an individual sire may achieve is dictated by uncompensable semen quality factors, the fertility potential of the female population, or both. Uncompensable traits are largely associated with abnormal sperm morphology, DNA integrity, or both and an inability of sperm to maintain embryonic development postfertilization (Saacke, 1998). The concept that the female population places a biological limit on fertility responses to sperm dosage and semen quality has been emphasized by both Salisbury and Van Demark (1961) and Saacke (1998), although examples of such effects in practice are limited.

In the present study, the heifer data presented in Figure 1 illustrate the classic variation in fertility response to sperm dosage that Salisbury and Van Demark would predict. Sire A evidently possessed few uncompensable sperm defects and exhibited a nearly linear response to increasing sperm dosage while achieving the greatest overall conception of the 3 sires compared. Although sire B appeared to have slightly more compen- sable sperm defects (i.e., numerically lower conception at $2.1 \times 10^{6}$ sperm dosage), both sires $\mathrm{B}$ and $\mathrm{C}$ appeared to possess a comparable level of uncompensable defects, as evidenced by the comparable level of fertility at dosages $\geq 3.5 \times 10^{6}$. Interestingly, although sire A appeared to be more responsive to increasing sperm dosages, least squares means analysis actually indicated that sire C tended to have the greatest overall conception rate, presumably because of the lack of sensitivity to sperm dosage and thereby the relative absence of decreased conception caused by lower sperm dosages.

The observation that each sire appeared to reach a fertility plateau within the range of 2.1 to $5.0 \times 10$ sperm per dose is consistent with other dose titration studies using conventional semen in lactating cows (van Giessen et al., 1992; den Daas et al., 1998). Because a nonsorted control was not used in the current study, it is not clear from these data whether the maximum fertility potential of each sire (i.e., uncompensable semen quality traits) was influenced by the sorting procedure. The maximum fertility levels achieved by sires B and $\mathrm{C}$ at the highest sperm dosage were considerably lower than that for sire A and were lower than that obtained with conventional semen used in these same herds ( $\sim 58$ to $60 \%)$. Sartori et al. (2004) observed an increased incidence of unfertilized and degenerate embryos after superovulation and insemination with sexsorted semen, suggesting that the sorting procedure compromised both compensable and uncompensable se- 
men quality traits. Thus, it is possible that the different dose-response curves for sire A vs. sires B and C may reflect the sensitivity of the respective sires to degradation in semen quality in response to sorting and may not be consistent with dose-response curves that would be produced by unsorted semen.

In a series of 6 trials, Seidel and Schenk (2007) evaluated the effects of sexed-sperm dosage over a range of 1.5 to $6 \times 10^{6}$ sperm per dose when used in beef heifers, dairy heifers, or beef cows. Although they found limited evidence to support a conception response to increasing sperm dosages, many trials were of small sample size ( $\mathrm{n} \leq 125$ sperm dosage/sire within trial) and lacked statistical power to confirm numeric trends that occasionally appear to exist. Specifically, in a comparison of 1.5 vs. $6.0 \times 10^{6}$ sexed-sperm dosages across 4 Holstein sires after use in virgin Holstein heifers, a single sire achieved conception rates ( 48 vs. $57 \%$, respectively) that were nearly identical to the 2.1 and $5.0 \times 10^{6}$ sperm dosages of sire A in the present study. Perhaps the sample size in the previous study $(\mathrm{n}=101$ and 75 , respectively) diminished the statistical power to detect this as a meaningful difference. These authors also identified both sire and herd effects that were similar to those noted in the present trial.

Even though the same ejaculates from the same sires were used in lactating cows as were used in heifers, the dose-response curve was not evident in lactating cow data (Figure 2). This does not necessarily imply that lactating cows respond differently to sperm dosage compared with heifers. To the contrary, this observation may be interpreted as confirming Salisbury and Van Demark's (1961) hypothesis that the fertility potential of the female population under study places biological limits on the ability of semen quality characteristics to affect the observed fertility response. Semen quality and sperm numbers are likely equally relevant in cows and in heifers; however, other extrinsic or environmental factors are more limiting to conception potential, which thereby diminishes our ability to detect conception rate differences associated with the inseminate.

Across sperm dosages, conception rates of lactating cows were comparable to those previously reported with $2.1 \times 10^{6}$ dosages of sex-sorted sperm (Schenk and Everett, 2007) and, as a percentage of that achieved with conventional semen, were similar to those reported for use in virgin heifers (i.e., 75 to $80 \%$ of that achieved with conventional semen, Garner and Seidel, 2002; DeJarnette et al., 2007; Seidel and Schenk, 2007). Thus, the most enlightening implication of this study may be that the creation of a separate sperm dosage for use of sex-sorted semen in lactating cows vs. virgin heifers may not be necessary. However, this should not be in- terpreted as implying that the economic returns from use of sexed semen in lactating cows are similar to those in virgin heifers. To the contrary, the opportunity for a return on investment from sex-sorted semen is highly dependent on the actual conception rate achieved in addition to other factors, including the differential value of calf sex, semen price, and the genetic merit of the female being inseminated (Seidel, 2003; Olynk and Wolf, 2006; Fetrow et al., 2007). In addition, with consideration for efficient industry use of a limited supply resource, a given amount of sex-sorted semen used in cows will result in a number of heifer calves that are approximately $64 \%(\sim 29 \%$ conception $\times 90 \%$ heifers $=$ 0.26 heifers per dose of semen) of the amount that would be produced if that same volume of semen were used in virgin heifers $(45 \%$ conception $\times 90 \%$ heifers $=0.405$ heifers per dose of semen).

Similarly, although conception in virgin heifers appears to be increased in some sires with greater sperm number dosages, the current status of sex-sorting efficiency would likely dictate a production and retail cost that would more than offset any improvement in reproductive efficiency. The commercial availability of sexsorted sperm is presently limited by the number of sorting machines in production facilities and the amount of sorting time required to process each dose. The production cost of sexed semen is in turn dictated by the high initial investment cost ( $\$ 400,000 /$ sorter $)$, the fixed cost of labor and overhead, and the number of doses that can be produced in a given period of sorting time. Thus, for example, if an increase in sex-sorted sperm numbers from 2.1 to $3.5 \times 10^{6}$ sperm per dose were actually to yield a $5 \%$ increase in conception rate among virgin heifers, this would require a $67 \%$ increase in machine processing time per dose of semen and a resultant $40 \%$ reduction in the total number of doses processed during a given period of time. Assuming $90 \%$ heifers, 100 doses at $2.1 \times 10^{6}$ per dose $\left(210 \times 10^{6}\right.$ total sorted sperm) would provide the industry with 40.5 heifer calves (100 doses $\times 45 \%$ conception rate $\times 90 \%$ heifers), whereas this same volume of time (semen) at $3.5 \times 10^{6}$ sperm per dose would provide the industry with only 27 heifers $\left(210 \times 10^{6}\right.$ total sorted sperm/3.5 $\times 10^{6}$ sperm per dose $=60$ doses $\times 50 \%$ conception rate $\times 90 \%$ heifers). This translates into a 33\% reduction in the total number of heifer calves in exchange for a significant increase in the total cost of production. The repeatability of these results across a wider range of sires should be extensively studied from both a physiological and economic perspective before any changes to the current processing procedures can be recommended.

In the present study, no attempt was made to statistically compare conception rates of sex-sorted semen with 
those of conventional semen from other sires because of the known bias toward preferential use of sex-sorted semen in females that should have a greater potential for conception. This bias was particularly evident in the heifers in the present study, in which those bred to conventional semen averaged $40 \mathrm{~d}$ older at $\mathrm{AI}$ and achieved only $46 \%$ conception despite preliminary herd selection for the ability to achieve $60 \%$ conception by using conventional semen. This observational anomaly, wherein conception rates to conventional semen appear to decline upon introduction of sex-sorted semen to the herd, has been alluded to in previous reports (DeJarnette et al., 2007) and is likely an artifact of fertility bias created in selecting which heifers should receive conventional semen (a disproportionate number of second and greater services, questionable signs of estrus, or both) vs. sex-sorted semen (a disproportionate number of first services, conclusive estrus diagnoses, or both). A decisive comparison of sexed and conventional semen in an on-farm setting would require a nonsorted conventional treatment that would be blind to the end user, which was beyond the scope of the objectives for the present trial.

The variation in conception rates achieved among both cow (15 to $41 \%$ ) and heifer (33 to $68 \%$ ) herds in the present study, despite the use of sex-sorted semen from a common sample of sires and experimental pool, may indicate that considerable opportunities exist to enhance the efficiency of commercial application of sexsorted semen through identification of on-farm management techniques and procedures that are conducive to more optimal fertility potential in the female population. This is further supported by the observation of very similar ranges in conception rates $(21$ to $39 \%$ and 29 to $61 \%$ for cows and heifers, respectively) with the use of conventional semen at presumably much higher sperm dosages (15 to $20 \times 10^{6}$; Vishwanath, 2003).

\section{CONCLUSIONS}

Conception rates among virgin heifers were influenced by the sire $\times$ sperm dosage interaction. Although the conception rates of one sire responded positively to an increasing sperm dose, those of the other 2 sires were not affected. Neither sire nor sperm dosage affected conception rates of lactating cows inseminated with sexsorted semen, which indicates that separate insemination dosages for the use of sex-sorted semen in lactating cows (as opposed to virgin heifers) is not necessary. This observation does not imply that comparable economic returns are available from using sex-sorted semen in both cows and heifers. Although a greater sperm dosage may slightly improve heifer conception rates for some sires, the efficiency of sex-sorting technology at present is likely cost prohibitive to capitalizing on this opportunity. Perhaps advances in sorting efficiency may eventually lend themselves to the more cost-effective production of higher sperm number dosages, whereas additional semen processing and cryopreservation research may allow for more optimal conception at low sperm number dosages.

\section{ACKNOWLEDGMENTS}

The authors would like to thank the owners and staff of the many Select Sires' Program for Fertility Advancement (PFA) herds that cooperated in this project as well as the numerous staff and PFA coordinators for their invaluable assistance. This includes, but is not limited to, Brad Meek, Cache Valley/Select Sires (Logan, UT); Jim Wells, All West/Select Sires (Turlock, CA); Adam Hahlen, COBA/Select Sires (Hilliard, OH); Matt Hershey and Dave Whitlock, Select Sire Power (Rocky Mount, VA); Steve Kacuba, East Central/Select Sires (Waupun, WI); Joe Fowler, Southeast/Select Sires (Spring Hill, TN); Butch Lerum and Lyle Kruse, Minnesota/Select Sires (St. Cloud, MN); and Julie Ainsworth, Northstar Cooperative (East Lansing, MI).

\section{REFERENCES}

Amann, R. P. 1999. Issues affecting commercialization of sexed sperm. Theriogenology 52:1441-1457.

Barth, A. D., and J. Oko. 1989. Abnormal Morphology of Bovine Spermatozoa. Iowa State University Press, Ames.

den Daas, J. H. G., G. de Jong, L. M. T. E. Lansbergen, and A. M. van Wagtendonk-de Leeuw. 1998. The relationship between the number of spermatozoa inseminated and the reproductive efficiency of individual dairy bulls. J. Dairy Sci. 81:1714-1723.

DeJarnette, J. M., R. L. Nebel, B. Meek, J. Wells, and C. E. Marshall. 2007. Commercial application of sex-sorted semen in Holstein heifers. J. Dairy Sci. 90(Suppl. 1):228. (Abstr.)

Fetrow, J., M. Overton, and S. Eicker. 2007. Sexed semen: Economics of a new technology. Bovine Pract. 41:88-99.

Garner, D. L., L. A. Johnson, S. Lake, N. Chaney, D. Stephenson, D. Pinkel, and B. L. Gledhill. 1983. Quantification of the X- and Ychromosome-bearing spermatozoa of domestic animals by flow cytometry. Biol. Reprod. 28:312-321.

Garner, D. L., and G. E. Seidel Jr. 2002. Current status of sexing mammalian spermatozoa. Reproduction 124:733-743.

Johnson, L. A., J. P. Flook, and H. W. Hawk. 1989. Sex preselection in rabbits: Live births from X and Y sperm separated by DNA and cell sorting. Biol. Reprod. 41:199-203.

Olynk, N. J., and C. A. Wolf. 2006. Expected net present value of pure and mixed sexed semen artificial insemination strategies if dairy heifers. J. Dairy Sci. 90:2569-2576.

Robbins, R. K., R. G. Saacke, and P. T. Chandler. 1976. Influence of freeze rate, thaw rate and glycerol level on acrosomal retention and survival of bovine spermatozoa frozen in French straws. J. Anim. Sci. 42:145-154.

Saacke, R. G. 1998. AI fertility: Are we getting the job done? Pages 6-13 in Proc. 17th Tech. Conf. Artif. Insem. Reprod., Natl. Assoc. Anim. Breeders, Columbia, MO.

Saacke, R. G., and C. E. Marshall. 1968. Observations on the acrosomal cap of fixed and unfixed spermatozoa. J. Reprod. Fertil. 17:511-514.

Salisbury, G. W., and N. L. Van Demark. 1961. Significance of semen quality. Pages 359-379 in Physiology of Reproduction and Artifi- 
cial Insemination in Cattle. 1st ed. W. H. Freeman and Co., San Francisco, CA.

Sartori, R., A. H. Souza, J. N. Guenther, D. Z. Caraviello, L. N. Geiger, J. L. Schenk, and M. C. Wiltbank. 2004. Fertilization rate and embryo quality n superovulated Holstein heifers artificially inseminated with X-sorted or unsorted sperm. Anim. Reprod. $1: 86-90$.

Schenk, J. L., and R. W. Everett. 2007. Insemination of Holstein cows with sexed sperm. J. Dairy Sci. 90(Suppl. 1):18. (Abstr.)

Schenk, J. L., T. K. Suh, D. G. Cran, and G. E. Seidel Jr. 1999. Cryopreservation of flow-sorted bovine spermatozoa. Theriogenology 52:1375-1391.

Seidel, G. E., Jr. 2003. Economics of selecting for sex: The most important genetic trait. Theriogenology 59:585-598.

Seidel, G. E., Jr. 2007. Overview of sexing sperm. Theriogenology 68:443-446.
Seidel, G. E., Jr., and D. L. Garner. 2002. Current status of sexing mammalian spermatozoa. Reproduction 124:733-743.

Seidel, G. E., Jr., and J. L. Schenk. 2007. Pregnancy rates in cattle with cryopreserved sexed sperm: Effects of sperm numbers per inseminate and sire of sperm deposition. Anim. Reprod. Sci. [Epub ahead of print]

Seidel, G. E., Jr., J. L. Schenk, L. A. Herickhoff, S. P. Doyle, Z. Brink, R. D. Green, and D. G. Cran. 1999. Insemination of heifers with sexed sperm. Theriogenology 52:1407-1420.

van Giessen, R. C., C. A. Zuidberg, W. Wilmink, W. Veene, and N. den Daas. 1992. Optimum use of a bull with high genetics. Page 1493 in Proc. XII Int. Congr. Anim. Reprod. Artif. Insem., the Hague, the Netherlands. Vol. 3.

Vishwanath, R. 2003. Artificial insemination: The state of the art. Theriogenology 59:571-584.

Welch, G. R., and L. A. Johnson. 1999. Sex preselection: Laboratory validation of the sperm sex ratio of flow-sorted X- and Y-sperm by sort reanalysis for DNA. Theriogenology 52:1343-1352. 